\title{
Trainees in a Therapeutic Community for Adolescents
}

\author{
Peter Wells, Consultant in Adolescent Psychiatry, Parkside Hospital, Macclesfield
}

The experience of working with disturbed adolescentsmany of whom manifest conduct disorders-in a therapeutic community is in many respects contrasting and different from the more conventional psychiatric setting. Studies have shown that doctors' attitudes to the therapeutic community approach are very polarized,' as are attitudes to psychological and organic methods. ${ }^{2}$ When faced with a choice of using psychotherapy, behaviour therapy, social psychiatry, or biological methods, doctors again exhibit strong preferences. $^{3}$ The opportunity to experience therapeutic community methods is not usually available in teaching hospitals, and is not uncommonly a source of friction when sited in a hospital.4 Relationships between psychotherapists and other psychiatrists in teaching hospitals are not always harmonious.'

The Young People's Unit, Macclesfield, was opened in 1970 to provide short-term residential treatment for 20 adolescents between the ages of 13 and 17 . The treatment setting has been described more fully elsewhere. ${ }^{6,7}$ Although run on therapeutic community lines, the four basic principles of such communities ${ }^{8}$ have been considerably modified to meet the needs of adolescents', particularly with regard to limit setting. Weekly sensitivity meetings and a weekly staff development group have been provided to meet some staff needs.

Since 1970 the Unit has been closely associated with the Manchester University Department of Psychiatry training scheme for psychiatric registrars; these rotate to the YPU every six months. Senior registrars also rotate to the YPU from the Manchester Child and Adolescent Psychiatry Training Scheme. Both schemes have been approved by the relevant national committees.

As doctors appear to show a strong preference for one or another model, and since the YPU provides one with which most doctors on the Manchester rotation scheme will not be familiar, it was felt that their response to the training they received on the YPU might be of general interest. Of particular interest is the value of exposing doctors to an alternative model of work, whether such an experience is helpful and whether it is relevant to what most of them expect to have to do when they become consultants.

\section{Survey of junior doctors}

Since 1975 each doctor who has worked on the Unit has been invited to fill in a questionnaire not less than four weeks after leaving. Doctors who worked on the Unit before 1975 (about one third) were also included in the survey.

Of $\mathbf{3 0}$ doctors included in the study, 28 working for $\mathbf{3 0}$ training periods on the Unit between 1970 and 1983 returned their questionnaires. Doctors were asked to respond to 141 questions covering all aspects of their training. This included:

1. Three aspects of teaching: teaching on new cases, on on going cases, and in more general subjects in the doctors' weekly meeting.

2. Eight aspects of training: training in management, training in the two weekly counselling workshops, in group therapy, in multi-family group therapy, in family therapy, in gaining therapeutic skills, in understanding adolescents, and in the use of controls.

3. Two aspects of personal growth (see Table I for results of (1), (2) and (3)).

4. A section on therapeutic community asked questions on how familiar responders were with this approach, its relevance to work with adolescents, whether a doctor's role on the Unit was clear or not, and whether their Unit role helped or hindered working with other staff and the resident youngsters. Questions also dealt with powersharing with other disciplines, the value doctors placed on contributions made by other staff in discussion of clinical and other problems, whether their experience of Unit meetings resulted in their being more open or more inhibited, whether it increased or diminished self-awareness, and its effect on their anxiety level. Doctors were asked if support from other staff was 'full', 'adequate', 'inadequate', or 'wholly lacking'.

5. Further sections asked for career details, what determining influence the YPU had on subsequent choice of career and the effect, if any, of working on the Unit on prospects for promotion; whether attitudes to other staff had changed since leaving, and whether there had been any subsequent opportunity to practice skills learned on the Unit.

6. There were questions on the opportunities and encouragement to carry out research, on library facilities at the Unit, and on an annual winter lecture series.

Responders were asked to rate most components of their training on a scale 0 to 5 , coded as 'very poor' or 'nonexistent', 'poor', 'below average', 'average', 'above average',

TABLE I

Junior doctors' evaluation of their training

\begin{tabular}{|c|c|c|c|c|c|c|}
\hline & \multicolumn{6}{|c|}{$\begin{array}{l}\text { Percentages of total responses } \\
\text { in each category }\end{array}$} \\
\hline & 0 & 1 & 2 & 3 & 4 & 5 \\
\hline 3 aspects of teaching & 0 & 1 & 8 & 33 & 47 & 11 \\
\hline $\begin{array}{l}8 \text { aspects of training } \\
2 \text { aspects of }\end{array}$ & 0.5 & 5 & 13.5 & 28 & 40 & 13 \\
\hline personal growth & 5 & 3 & 14 & 32 & 32 & 14 \\
\hline
\end{tabular}


and 'superior'. Other questions provided a suitable range of alternatives and there were spaces inviting additional comments.

\section{Junior doctors' views}

Although far more information was obtained than can be accommodated in a short article (the full survey may be obtained on application to the author), Table I summarizes a representative sample of responses to some of the questions. This demonstrates that most trainees were satisfied with their overall experience of working in a therapeutic community with disturbed adolescents. As might be expected, the majority stated that their previous training failed to prepare them adequately for work in a therapeutic community, although only half in practice experienced difficulty in adjusting to their new role. In view of this it is reassuring that 24 juniors considered that the support they received from the Unit staff was 'full' or 'adequate'. None rated it 'totally lacking.' It appears that juniors can cope with a different role providing the support they are given is appropriate, and those who regarded their role primarily as trainee therapist coped most successfully.

A change of role to one more open to challenge or criticism from non-medical members of the team can be anxiety-provoking. A support system needs to be available which not only accepts that anxiety is a normal part of personal development, but can prevent it becoming disabling. Nevertheless there are some senior colleagues who regard the trainee's personal development as a private, not a training matter. Accordingly, junior doctors were asked whether they were aware of gaining mastery over certain anxiety-provoking situations, such as talking in large meetings, confronting adolescents and tolerance of actingout behaviour.

Questions were also asked about increased self-awareness, tolerance of their own anxiety and the support received from other staff. One third of the doctors agreed that working on the Unit had a strong to maximal effect on their own personal growth process. Practically all felt that they had rotated to the Unit at the right phase of their training and development; three stipulated that any earlier rotation to the Unit would not have been so beneficial. (Registrars rotate to the Unit on average 18 months after starting psychiatry, and six months after promotion to Registrar). There is reason to suppose that had the Unit regarded the emotional and developmental processes of juniors as entirely their own business, some doctors, working so closely with emotionally disturbed teenagers, would have felt very exposed and unsupported.

Another area of difficulty for doctors was the notion of power-sharing with a team when making decisions. Seventeen out of 26 respondents, however, came to value this approach, and 21 felt that the value they placed on contributions to discussion by non-medical staff increased (five recorded no change).
The majority of trainees came to favour a family meeting rather than a purely diagnostic one in assessing adolescents referred for admission, although there were anxieties over missing important medical or psychiatric cues should they become too immersed in the family pathology. A few also seemed to expect a text-book pattern to follow and were unhappy when exposed to heuristic methods.

It seemed legitimate to enquire whether doctors influenced by working with adolescents in a modified therapeutic community, might return to a more conventional setting with abrasive views, particularly about traditional kinds of authority. Comments reveal a greatly changed, more appreciative and less inhibited approach to others, including their senior colleagues, since leaving the Unit. Their training clearly had a very positive effect on doctors in developing confidence and in relating successfully with a team.

They were also asked if working on the Unit exerted a deleterious effect on their career prospects. Only one felt that promotion prospects were 'probably less', whereas two regarded them as 'greatly improved', 12 'probably improved' and 14 felt them to be unaffected.

As some may question whether training in a therapeutic community setting is relevant to what most doctors returning to general psychiatry may subsequently expect to have to do, juniors were asked which of a selection of major therapeutic skills taught at the YPU they were able to use in their further career. The majority subsequently practised four out of a sample of five skills taught on the Unit (individual psychotherapy, group therapy, family therapy and community meetings for the staff and patients). This is a relevant finding, given that the majority of respondents had only experienced one new post since leaving the Unit.

In addition, about one-third of the 21 registrars who rotated from general psychiatry, stated that their experience of working on the Unit exerted a strong determining influence on their deciding to choose to specialize in child and adolescent psychiatry. Seven registrars to date are known to have actually joined the specialty. Three out of seven senior registrars stated that they preferred to work in adolescent psychiatry rather than in child and adolescent psychiatry as a result of working on the Unit. Currently there are only 0.9 applicants per consultant post in the specialty. ${ }^{10}$ The finding that the experience of working with adolescents in a therapeutic community setting provided an incentive to doctors to join a shortage specialty is another useful indicator of its value.

It is concluded that working in a modified therapeutic community for disturbed adolescents can be both useful and relevant to the training of junior doctors, and is likely to receive support from the profession, providing that these two components are regularly appraised.

\section{REFERENCES}

'CAINE, T. M. \& SMAII, D. J. (1966) Attitudes to treatment of medical staff in therapeutic communities. British Journal of Medical Psychology, 39, 329-34. 
${ }^{2}$ Krertman, N. (1962) Psychiatric orientation: A study of attitudes among psychiatrists. Journal of Mental Science, 108, 317-28.

${ }^{3}$ Toone, B. K., Murray, R., Clare, A., Creed, F. \& Smith, A (1979) Psychiatrists' models of mental illness and their personal backgrounds. Psychological Medicine, 9, 165-78.

'Pines, M. (1979) Chapter in Therapeutic Communities (eds. R. D. Hinshelwood and F. Manning). London: Routledge \& Kegan Paul.

'Lieberman, S. \& CoBb, J. (1983) Psychotherapy supervision: The attitudes of general psychiatrists. Bulletin of the Royal College of Psychiatrists, 7, 102-3.

'Wells, P. G., MorRis, A., Jones, R. M. \& Allen, D. J. (1978)
An adolescent unit assessed: A consumer study. British Journal of Psychiatry, 132, 300-8.

'Jones, R. M., Allen, D. J., Wells, P. G. \& MorRis, A. (1978) An adolescent unit assessed: Attitudes to a treatment experience for adolescents and their families. Journal of Adolescence, 2, 371-83.

'RAPOPORT, R. M. (1960) Community as Doctor. London: Tavistock.

${ }^{9}$ Wells, P. G. (1981) Adolescents in large groups: Confirming a model. Social Work with Groups, 4, 63-8.

${ }^{10}$ DHSS (1983) Medical and dental staffing prospects in the NHS in England and Wales, 1982. Health Trends, 15, 35-9.

\title{
Training in Psychiatry for Developing Countries (with special reference to Africa)
}

\author{
JoHN L. Cox, Senior Lecturer, Royal Edinburgh Hospital, Edinburgh
}

It was bold, as well as shrewd, to have held the 4th Conference of the African Psychiatry Association in London (Institute of Psychiatry) rather than Lagos or Lusaka. Yet Dr A. C. Raman (Consultant, St Augustine's Hospital and Secretary General of the Association) should be well satisfied with the rewards for his hard work. There were about 100 participants (the majority from Africa) who debated with vigour and courtesy the diverse facets of the conference theme. To have discussed these controversial training matters at the institution which, together with the department of psychiatry in Edinburgh, had influenced considerably the development of psychiatry in Nigeria, as well as in other Anglophone African countries, could have misfired. However, for most participants the conference presented a rare opportunity for legitimate nostalgia, as well as the chance to contribute to discussion on the present training of psychiatrists in Africa.

The conference proceeded with its work under the eagle eye of its President, Professor Binitie from Nigeria, with Dr Raman as both the organizing secretary and translator of the English and French language. The participants were indeed an unusual amalgam of African psychiatrists (predominantly from Nigeria), Europeans currently working in Africa, and at least one psychiatrist (Dr Ben-Tovim) who had recently returned to the UK from Botswana.

Several African trainees working in London were present as well as two African Consultants from the Kingdom of Fife in Scotland and from the London commuter zone of Woodford Green. They added considerably to the poignancy of the conference debate about training and by their presence illustrated its hidden agenda.

Some of the other participants were the pioneers of African psychiatry, including Professors Tolani Asuni, Allen German and Alexander Borofika. Tribute was also given at the opening session by Dr Momar Gueye to the memory of Professor Henri Collomb from Senegal, and by Professor German to Dr Joseph Muhangi from Uganda.

Once the initial formalities were over, and the Canterbury and Thanet Health Authority put on the map, participants then tackled their main agenda, the underlying theme being the appropriateness of psychiatric training in Britain for work in Africa, methods of evaluating such programmes and the differences between training courses on offer from UK teaching centres. The relevance of psychoanalysis for training African psychiatrists was also discussed and, though questioned by some, was vigorously defended by others; the delegates from French-speaking African countries being vociferous in advocating the value of a psychoanalytic approach to patient management.

However, the most important issue discussed, and predictably the most controversial, was the proposal by the Institute of Psychiatry to establish a two-year diploma in Psychological Medicine to meet the specific training needs of overseas psychiatrists. Professor G. Russell (Institute of Psychiatry) introduced this proposal cautiously and explained that much thought had already been given to this new course which was being put forward because of recent criticism of the teaching of overseas psychiatrists, increased difficulty of the MRCPsych, termination of the conjoint DPM and the need to develop training that was more suitable for the work of an overseas psychiatrist.

The audience listened to this suggestion, attempted to understand its origins, but disagreed with its main tenets. The objections were couched politely and hinged around the belief that African trainees, who were the future leaders of psychiatry in their countries, needed a thorough and vigorous training. Professor Ebie from Nigeria pointed out that the levels of clinical responsibility for an African 